\title{
The prescription opioid epidemic: an update
}

This article was published in the following Dove Press journal:

Medicolegal and Bioethics

\section{Geoffrey Poitras}

Faculty of Business Administration, Simon Fraser University, Vancouver, BC, Canada
Correspondence: Geoffrey Poitras Faculty of Business Administration, Simon Fraser University, Vancouver, BC V5A

IS6, Canada

Email poitras@sfu.ca
Background: Since a previous contribution to this journal in 2012, the epidemic of opioid abuse has become increasingly frightening and tragic. Of an estimated 62,632 drug overdose deaths in the US in 2016 about 2/3 were from opioids, more than deaths from traffic fatalities. Preliminary data for 2017 indicates an even higher opioid overdose death count.

Methods: This paper reviews available data from public health agencies and other sources detailing the significant changes in both the regulatory response and characteristics of the opioid overdose epidemic. While discussion provided is primarily for the US, where the epidemic is centered, results from other countries, such as Canada, are also examined.

Results: The available data indicates a dramatic evolution in both the characteristics of the epidemic and the legal fallout for companies involved in providing prescription opioids. Regulatory efforts to control the supply of prescription opioids, such as revised guidelines for physicians employing opioids in pain management, combined with an avalanche of lawsuits against companies involved in the prescription opioid supply chain, has resulted in a frightening shift in to fentanyl-contaminated black market opioids by addicted populations.

Conclusion: The shift to black market opioids has created an even more complicated regulatory problem, exposing the deep societal problems that underpin the epidemic. While attempts to address this new stage of the epidemic, including the widespread use and availability of naloxone, creating of drug injection sites, passage of 'Good Samaritan' laws and the like, have not been accompanied by a commensurate reduction in the overdose death rate.

Keywords: medicalization, opioid abuse, shareholder wealth maximization

The Angelic face of Opium is dazzlingly seductive, but if you look on the other side of the coin, it will appear altogether a Devil. There is so much poison in this All-healing Medicine that we ought not to be by any means secure or confident in the frequent and familiar use of it.

Thomas Willis, MD (1674) ${ }^{1}$

\section{Introduction}

Since a previous contribution to this journal in $2012,{ }^{2}$ the epidemic of opioid abuse has become increasingly frightening and tragic. That contribution focused on the relevance of OxyContin to prescription opioid diversion and abuse, the marketing tactics employed by pharmaceutical companies to promote products, and the associated economic medicalization of substance abuse and addiction. This update details dramatic changes in the epidemic and explores attempts being made to combat the rising opioid overdose death toll. Important legal developments arising from the marketing and distribution of prescription opioids are overviewed. Specifically, the prolifera- 
tion of legal actions against firms involved in the epidemic has resulted in the consolidation of claims in a multidistrict litigation (MDA). The difficulty of stemming the epidemic through legal avenues shifts attention to recent attempts by regulators to stem the epidemic. The paper concludes with some pessimistic observations about the difficulties of using "harm reduction" solutions to address substance abuse and addiction problems with deep societal roots.

Reviewing the increase in US drug overdose deaths from 2000 to 2014, the Centers for Disease Control and Prevention (CDC) reported that "there were approximately one and a half times more drug overdose deaths in the United States than deaths from motor vehicle crashes." ${ }^{3}$ Opioids, primarily prescription pain relievers, and heroin were the main drugs associated with overdose deaths. In 2014, a year in which 28,647 persons died from opioid drug overdoses in the United States, more than any year on record to that point, opioids were involved in $61 \%$ of the 47,055 drug overdose deaths, a number that was more than triple of the 8,407 opioid overdose deaths of 2000. The CDC observed that, in 2014, the opioid overdose epidemic had two "distinct but interrelated trends: a 15-year increase in overdose deaths involving prescription opioid pain relievers and a recent surge in illicit opioid overdose deaths, driven largely by heroin". ${ }^{3}$ The ensuing avalanche of overdose deaths from largely illegal, nonprescription synthetic opioids, primarily fentanyl and related derivatives - from 5,544 overdose deaths in 2014 to 19,413 in 2016 - was not adequately anticipated (see Figure 1 and Table 1), if only because deaths from nonmedical use do not fall within the purview of the medical profession.

Though the largest source of increase in the rate of drug overdose deaths from 2013 to 2014 involved synthetic opioids other than methadone, such as fentanyl and tramadol, nearly doubling from 1.0 to 1.8 per $1,00,000$, it was heroin overdose death rates increasing by $26 \%$ from 2013 to 2014 and more than tripling since 2010 , from 1.0 to 3.4 per $1,00,000$, that attracted attention in the CDC report. Significantly, the epidemic of natural and semisynthetic prescription opioids, such as morphine, oxycodone, and hydrocodone, at 3.8 per 1,00,000, was still the highest source of opioid overdose deaths in 2014, an increase of $9 \%$ from $2013 .^{3}$ The regulatory response at the federal level, led by the various divisions of the Department of Health and Human Services (HHS), aimed primarily at reducing prescription opioid supply by adjusting the pain management prescription practices of physicians combined with enhanced addiction treatment and education strategies. The ineffectiveness of this response at reaching those involved in the "nonmedical" use of opioids is reflected in the increas-

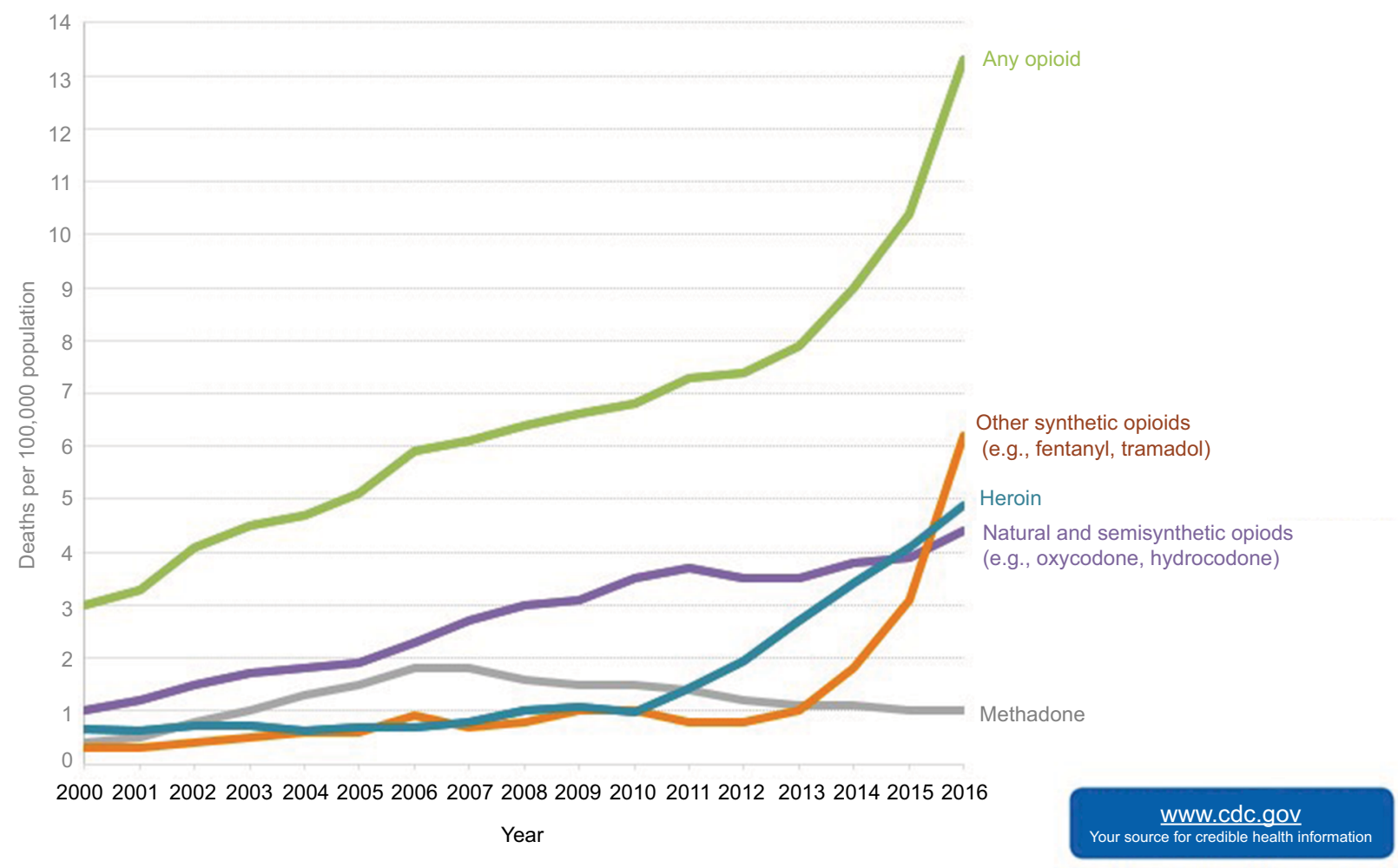

Figure I Overdose deaths involving opioids by type of opioid, United States, 2000-2016.

Note: Hedegaard H, Warner M, Miniño AM. Drug overdose deaths in the United States, 1999-2016. NCHS Data Brief, no 294. Hyattsville, MD: National Center for Health Statistics. $2017 .^{58}$ 
Table I Opioid Overdose Deaths in the United States, 1999-2016

\begin{tabular}{|c|c|c|c|c|c|c|c|c|c|c|}
\hline \multirow[t]{2}{*}{ Year } & \multicolumn{2}{|c|}{ Any opioid } & \multicolumn{2}{|l|}{ Heroin } & \multicolumn{2}{|c|}{$\begin{array}{l}\text { Natural and } \\
\text { semisynthetic opioids }\end{array}$} & \multicolumn{2}{|c|}{ Methadone } & \multicolumn{2}{|c|}{$\begin{array}{l}\text { Synthetic opioids other } \\
\text { than methadone }\end{array}$} \\
\hline & Number & $\begin{array}{l}\text { Deaths } \\
\text { per } \\
100,000\end{array}$ & Number & $\begin{array}{l}\text { Deaths } \\
\text { per } \\
100,000\end{array}$ & Number & $\begin{array}{l}\text { Deaths } \\
\text { per } \\
100,000\end{array}$ & Number & $\begin{array}{l}\text { Deaths } \\
\text { per } \\
100,000\end{array}$ & Number & $\begin{array}{l}\text { Deaths per } \\
100,000\end{array}$ \\
\hline 1999 & 8,050 & 2.9 & 1,960 & 0.7 & 2,749 & 1.0 & 784 & 0.3 & 730 & 0.3 \\
\hline 2000 & 8,407 & 3.0 & $\mathrm{I}, 842$ & 0.7 & 2,917 & 1.0 & 986 & 0.4 & 782 & 0.3 \\
\hline 2001 & 9,496 & 3.3 & $\mathrm{I}, 779$ & 0.6 & 3,479 & 1.2 & $\mathrm{I}, 456$ & 0.5 & 957 & 0.3 \\
\hline 2002 & II,920 & 4.1 & 2,089 & 0.7 & 4,416 & 1.5 & 2,358 & 0.8 & I,295 & 0.4 \\
\hline 2003 & 12,940 & 4.5 & 2,080 & 0.7 & 4,867 & 1.7 & 2,972 & 1.0 & 1,400 & 0.5 \\
\hline 2004 & 13,756 & 4.7 & 1,878 & 0.6 & 5,231 & 1.8 & 3,845 & 1.3 & 1,664 & 0.6 \\
\hline 2005 & $|4,9| 8$ & 5.1 & 2,009 & 0.7 & 5,774 & 1.9 & 4,460 & 1.5 & $\mathrm{I}, 742$ & 0.6 \\
\hline 2006 & 17,545 & 5.9 & 2,088 & 0.7 & 7,017 & 2.3 & 5,406 & 1.8 & 2,707 & 0.9 \\
\hline 2007 & $18,5 \mid 6$ & 6.1 & 2,399 & 0.8 & 8,158 & 2.7 & 5,518 & 1.8 & 2,213 & 0.7 \\
\hline 2008 & 19,582 & 6.4 & 3,041 & 1.0 & 9,119 & 3.0 & 4,924 & 1.6 & 2,306 & 0.8 \\
\hline 2009 & 20,422 & 6.6 & 3,278 & I.I & 9,735 & 3.1 & 4,696 & 1.5 & 2,946 & 1.0 \\
\hline 2010 & 21,089 & 6.8 & 3,036 & 1.0 & 10,943 & 3.5 & 4,577 & 1.5 & 3,007 & 1.0 \\
\hline 2011 & 22,784 & 7.3 & 4,397 & 1.4 & I I,693 & 3.7 & 4,418 & 1.4 & 2,666 & 0.8 \\
\hline 2012 & 23,166 & 7.4 & 5,925 & 1.9 & I I, | 40 & 3.5 & 3,932 & 1.2 & 2,628 & 0.8 \\
\hline 2013 & 25,052 & 7.9 & 8,257 & 2.7 & II,346 & 3.5 & 3,591 & I.I & 3,105 & 1.0 \\
\hline 2014 & 28,647 & 9.0 & 10,574 & 3.4 & 12,159 & 3.8 & 3,400 & I.I & 5,544 & 1.8 \\
\hline 2015 & 33,091 & 10.4 & 12,989 & 4.1 & 12,727 & 3.9 & 3,301 & 1.0 & 9,580 & 3.1 \\
\hline 2016 & 42,249 & 13.3 & 15,469 & 4.9 & 14,487 & 4.4 & 3,373 & 1.0 & 19,413 & 6.2 \\
\hline
\end{tabular}

Notes: NCHS Data Brief 294. Age-adjusted drug overdose death rates, by opioid category: United States, 1999-2016. Deaths are classified using the International Classification of Diseases, 10th Revision (ICD-10). Drug-poisoning (overdose) deaths are identified using ICD-10 underlying cause-of-death codes X40-X44, X60-X64, $\mathrm{X} 85$, and Y $10-Y \mid 4$. Among deaths with drug overdose as the underlying cause, the following multiple cause-of-death codes indicate the drug type(s) involved: any opioid (T40.0-T40.4, T40.6), heroin (T40.1), natural and semisynthetic opioids (T40.2), methadone (T40.3), and synthetic opioids other than methadone (T40.4). Deaths involving more than one opioid category (e.g., a death involving both methadone and a natural or semisynthetic opioid such as oxycodone) are counted in both categories. Natural and semisynthetic opioids include drugs such as morphine, oxycodone, and hydrocodone; and synthetic opioids other than methadone include drugs such as fentanyl, fentanyl analogs, and tramadol. The percentage of drug overdose deaths that identified the specific drugs involved varied by year, with ranges of $75 \%-79 \%$ from 1999 to 2013 , and 8I\%-85\% from 2014 to 2016. Hedegaard H, Warner M, Miniño AM. Drug overdose deaths in the United States, 1999-2016. NCHS Data Brief, no 294. Hyattsville, MD: National Center for Health Statistics. 2017. ${ }^{58}$

Source: NCHS, National Vital Statistics System, Mortality.

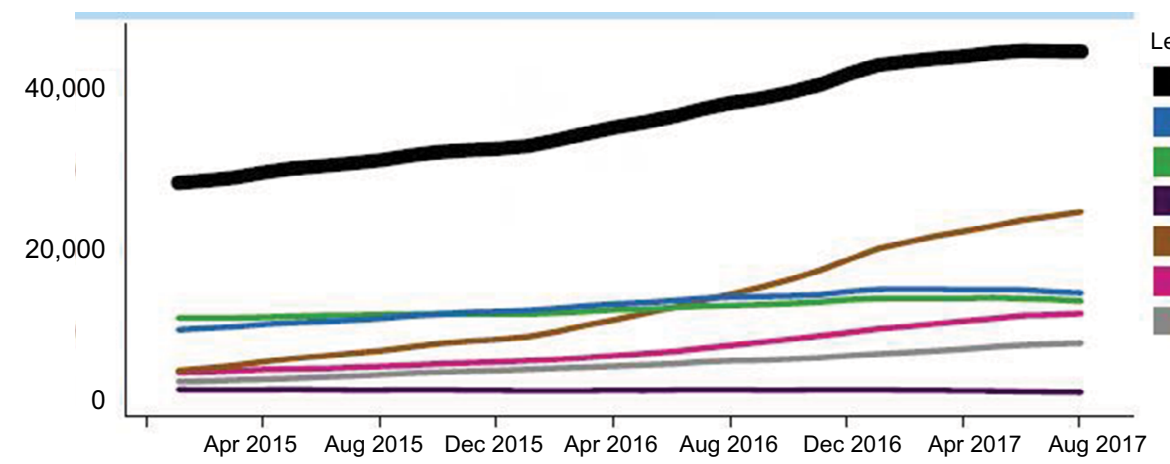

Legend for drug or drug class

Opioids (T40.0-T40.4,T40.6)

Heroin (T40.1)

Natural and semisynthetic opioids (T40.2)

Methadone (T40.3)

Synthetic opioids, excluding methadone (T40.4)

Cocaine (T40.5)

Psychostimulants with abuse potential (T43.6)

Figure 2 I 2 month-end provisional of drug overdose deaths, by drug or drug class; United States.

Note: See notes to Table I.

ing aggregate death toll. The November 2017 report of "The President's Commission on Combatting Drug Addiction and the Opioid Crisis"4 estimated the drug overdose death rate at 175 persons per day; about $2 / 3$ of the 62,632 overdose deaths were from opioids, translating to over 42,000 opioid overdose deaths for 2016. Available data for 2017 indicates an even higher opioid overdose death count (see Figure 2). By comparison, the National Safety Council reports just over 40,000 motor vehicle accident deaths in both 2016 and 2017.
The tragedy of opioid overdose deaths has attracted a vast literature dealing with various facets of the epidemic. Studies dealing with ethical concerns focus on the implications for the medical profession, and the ethical quandaries arising from the interaction between medical professionals and pharmaceutical manufacturers and distributors have largely been ignored. ${ }^{2,5-7}$ More precisely, there has been little recognition of the sharp ethical divergence between the goal of shareholder wealth maximization, associated with business 
ethics, and the norms of science and the scientific method, associated with medical ethics. The rise of prescription opioid abuse, and the subsequent tragedy of opioid overdose deaths, is an instance where a serious medical problem has been unnecessarily created as an outcome of firms pursuing the objective of shareholder wealth maximization influencing opioid prescription practices of physicians that, in turn, produced tragic behavioral responses. Of necessity, the abuse of prescription pain medication has required participation of the medical profession to legitimize the widespread use of opioids as the treatment of choice for chronic non-cancerrelated pain. Making allowances for the conduct of some unethical medical professionals and misinformation about opioid addiction risk provided by certain pharmaceutical companies, such participation has emerged despite the stringent code of ethics governing medical professionals.

In addition to actions of the medical profession, the regulators also have legal responsibility to adequately constrain profit-seeking pharmaceutical companies involved in promoting prescription opioids as the treatment of choice for noncancer pain management. Since the public policy disasters created by drugs such as elixir sulfanilamide in 1937 and thalidomide in the early 1960 s, it has been recognized that there is an inherent conflict of interest between private sector firms guided by the profit motive and those of the government to act in the "public interest" through regulatory oversight. ${ }^{8}$ In the case of prescription opioids, the corporate profit motive provided a strong incentive to develop an alternative delivery mechanism for an existing drug, resulting in the extended release formulation of oxycodone provided by OxyContin. Faced with a limited time to patent expiration and potential for erosion of the "first to market" profit margin advantage, there is great economic pressure on pharmaceutical companies to move drugs to market as quickly as possible and promote use once approved. Commercial rewards are more closely tied to the number of prescriptions written for a drug and the profit margin on those prescriptions than to the incremental medical value of the treatment.

The initial marketing of OxyContin by Purdue Pharma and the subsequent acceptance of prescription opioids as treatment of choice in pain management are unlike many other instances of drug uptake due to the long history of experience with the addictive properties of opium-based products; the Schedule II classification of opioid-derived prescription pain treatments; and, the large number of criminal and, especially, civil legal actions arising from the opioid epidemic. ${ }^{9}$ As detailed in the 2012 contribution, ${ }^{2}$ the marketing plans of companies involved in the production and distribution of prescription opioids have involved a variety of tactics that facilitated a dramatic increase in the supply of prescription opioids for the management of chronic non-cancer-related pain. Diversion of this increased supply led, de facto, to the medical profession extending control over a significant fraction of the nonmedical supply of opioids used by addicted populations, substituting for the use of heroin, cocaine, and methamphetamines. Subsequent effort to control diversion and overprescription to addicted populations has contributed significantly to the recent escalation in overdose deaths from black-market opioids.

The emergence of OxyContin and other prescription opioids as the drugs of choice for a range of substance abusers was a key element in the economic medicalization of opioid addiction and substance abuse that gained momentum during the first decade of the 21 st century. The National Center for Health Statistics (NCHS) reports that the number of unintentional overdose deaths from heroin stayed relatively constant from 1999 to 2006 at around 2,000 per year, increasing to just over 3,000 in 2010. ${ }^{10}$ During the same 2000-2010 period, the number of deaths from natural and semisynthetic opioids - effectively prescription opioid analgesics - more than quadrupled from less than 3,000 to about 12,000 per year. In comparison, synthetic opioids other than methadone increased from $<800$ to about 3,000. Comparing NCHS data for the first decade requires adjustment when interpreting 2011-2016 results as the total number of overdose deaths can count the same death twice if more than one type of opioid is involved. For 2000-2010, this double counting is not significant, for example, in 2010, 21,089 total deaths correspond to 21,563 deaths when deaths by type are summed (see Table 1). However, in 2016, 42,249 deaths translate to 52,742 deaths when deaths by type of opioid are summed. ${ }^{10}$ This difference of almost $25 \%$ largely captures the illegal mixing of fentanyl and related derivatives with other types of opioids to increase potency but not "polypharmacy" overdose deaths involving opioids mixed with other controlled substances such as benzodiazepines, cocaine, and methamphetamine (see Figure 3).

While the initial cause of the increase in opioid overdose deaths was largely driven by the medical profession expanding usage of prescription opioids such as oxycodone and methadone to manage long-term, noncancer-related pain, recent efforts to mitigate opioid prescription patterns have had some impact. Recognizing that opioid prescription data currently available are only up to 2015 , the CDC reports that "The amount of opioids prescribed in the United States peaked at 782 morphine milligram equivalents (MME) per capita in 2010 and then decreased to $640 \mathrm{MME}$ per capita in 2015." "To provide context on the dimension of this dosage: "700 $\mathrm{mg}$ of morphine per person is enough for 


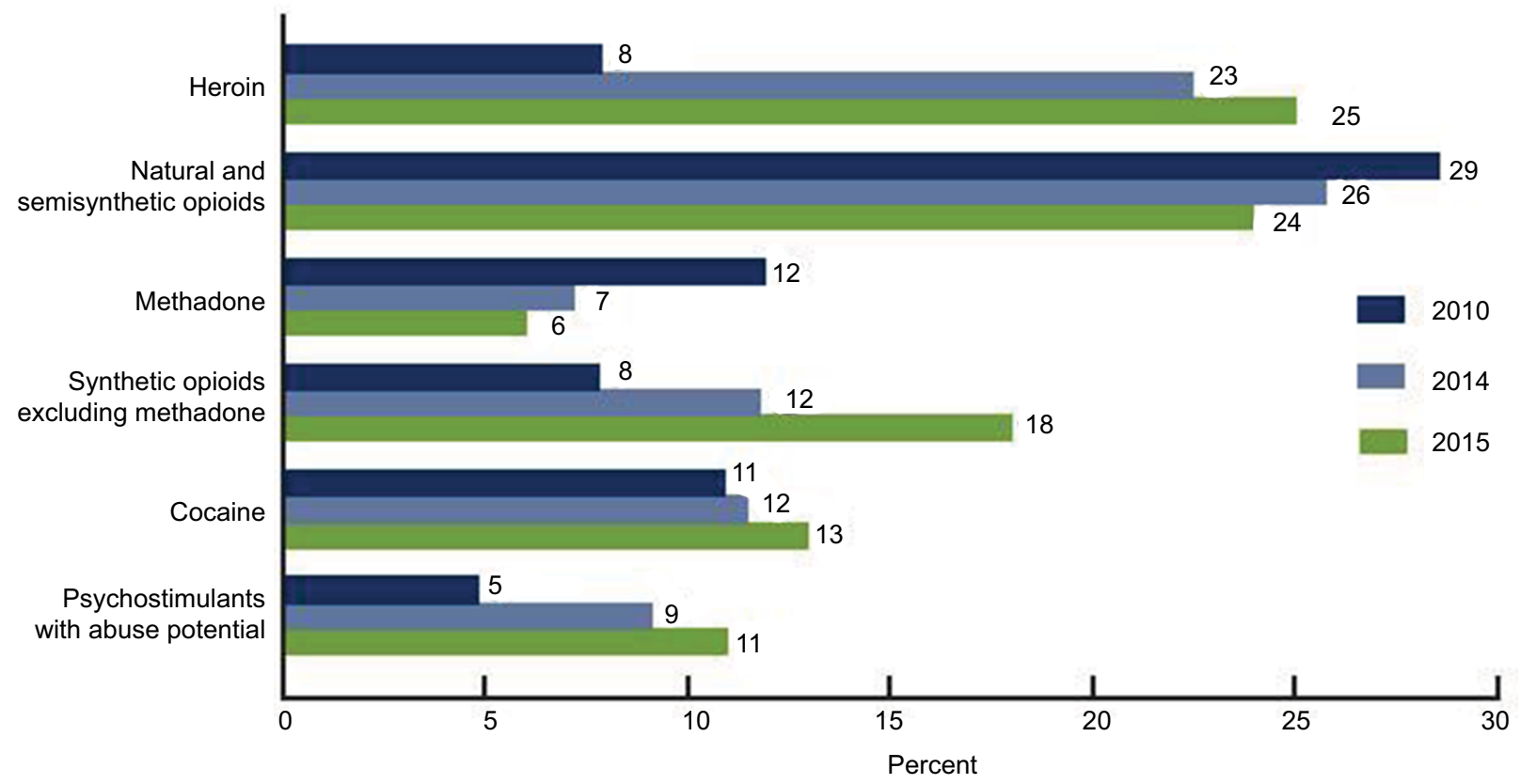

Figure 3 Drug overdose deaths in the United States, 2010-2015.

Notes: Deaths are classified using the International Classification of Diseases, Tenth Revision. Drug overdose deaths are identified using underlying cause-of-death codes X40-X44, X60-X64, X85, and Y I0-YI4. The total number of drug overdose deaths was 38,329 in 2010, 47,055 in 20I4, and 52,404 in 20I5. Drug overdose deaths involving selected drug categories are identified by specific multiple cause-of-death codes: heroin, T40.I; natural and semisynthetic opioids, T40.2; methadone, T40.3; synthetic opioids excluding methadone, T40.4; cocaine, T40.5; and psychostimulants with abuse potential, T43.6. Categories are not mutually exclusive because deaths may involve more than one drug. The percentage of drug overdose deaths lacking information on the specific drugs involved varied by year: $25 \%$ in 2010 , $19 \%$ in 2014 , and $17 \%$ in 2015 . Hedegaard H, Warner M, Miniño AM. Drug overdose deaths in the United States, 1999-2016. NCHS Data Brief, no 294. Hyattsville, MD: National Center for Health Statistics. 2017.58

everyone in the United States to take a typical $5 \mathrm{mg}$ dose of Vicodin (hydrocodone and acetaminophen) every 4 hours for 3 weeks". ${ }^{12}$ Though the per capita prescription supply has decreased somewhat, "the amount of opioids prescribed in 2015 remained approximately three times as high as in 1999 "16 and about 6.5 times the $96 \mathrm{mg}$ of morphine per person in $1997 .{ }^{17}$ The CDC also observes that "Persons who abuse opioids have learned to exploit this new practitioner sensitivity to patient pain, and clinicians struggle to treat patients without overprescribing these drugs." 12

The prescription opioid epidemic has not been confined to the United States, though the lighter regulation of promotion and pricing has made the United States an "ideal environment ... to produce an epidemic of overdose and addiction". ${ }^{13}$ The risk of the epidemic spreading to other countries inspired 12 members of the US Congress from areas hardest hit by the epidemic to write to the Director-General of the World Health Organization warning about the "dangerous" and "reckless" behavior of Purdue Pharma and the global counterpart group of companies, Mundipharma, both privately owned by the Sackler family. Faced with declining sales of OxyContin in the United States, a concerted effort is being made to increase global sales of prescription opioids using similar tactics employed in the marketing of OxyContin in the
United States. ${ }^{14}$ Detailing the opioid addiction and overdose epidemic on the global stage is decidedly more complex due to differing patterns of opioid usage. Countries such as Russia or Thailand located close to the sources of natural supply available to produce heroin, especially Myanmar and Afghanistan, tend to have a relatively lax enforcement, lower incomes, and porous borders that facilitate the use of nonprescription opioids..$^{15}$ Such countries would not be attractive targets for lucrative prescription opioid sales. The ten countries reporting the highest prescription opioid usage by rank are as follows: the United States, Canada, Germany, Denmark, Belgium, Austria, Switzerland, Australia, the Netherlands, and Spain. ${ }^{13}$

Any attempt at gaging the global spread of prescription opioid diversion and abuse needs to address data limitations. For example, based on data from the UN International Narcotics Control Board, one recent study for 2012-2014 identifies Canada as the country with the second highest prescription opioid usage having about $60 \%$ of the standard daily dose of prescription opioids per capita, ${ }^{13}$ while another recent study finds Canada with $732 \mathrm{mg}$ morphine equivalent per capita for 2014 (minus methadone), a number significantly higher than the United States. ${ }^{16}$ Compared with prescription patterns, data on opioid overdose deaths is relatively sparse. In contrast to the United States where the CDC provides detailed 
aggregate data, in Canada the provincial health authorities are responsible for such information making it difficult to determine aggregate results. In Germany, drug-associated deaths are reported by police departments, with heroin being the most reported cause of such deaths, suggesting substantial underreporting of deaths associated with prescription opioids. ${ }^{16}$ Another layer of complexity is added to the global opioid abuse epidemic by the sourcing of synthetic opioids from countries such as China, India, and Mexico where data reporting is largely absent.

\section{Legal fallout from marketing of prescription opioids}

In setting the legal and regulatory environment for the medical industry, governments are inclined to adhere to utilitarian ethics where decisions are often based on cost-benefit calculations. The precise method of determining costs and benefits can depend on a range of political and social factors, not just a dollar and sense calculation. In contrast to the AMA Code of Medical Ethics, the legal environment is a myriad of legislation and associated regulatory oversight established at different dates with potentially competing ethical standards. In the marketing, distribution, and consumption of Schedule II drugs, regulatory and legal oversight at the federal level in the United States would include the Congress, the Department of Justice (DOJ) and Drug Enforcement Agency, the Federal Trade Commission; the Office of National Drug Control Policy, a component of the White House, the National Institute on Drug Abuse, CDC, Centers for Medicare and Medicaid Services, the Food and Drug Administration (FDA), and Substance Abuse and Mental Health Services Administration, all housed within the HHS. In addition, there are similar state health agencies and criminal justice branches.

The history of OxyContin, a controlled-released version of the semisynthetic opioid oxycodone, is revealing. Initially developed in 1917, oxycodone is classified as Schedule II under the Controlled Substances Act (CSA) in the United States indicating a drug with high potential for abuse that does have legitimate medical applications. The CSA was introduced in 1970 as the American implementation of the Single Convention on Narcotic Drugs (1961), an international treaty prohibiting production and distribution of narcotics unlicensed for use. Having received FDA approval in 1995 for the management of chronic pain, with patent expiration extending to 2013, the aggressive marketing campaign pursued by the privately held Purdue Pharma resulted in a sales increase from $\$ 44$ million and 3,16,000 prescriptions in 1996 to a combined total of nearly $\$ 3$ billion and 14 million prescriptions by 2001 and 2002. ${ }^{9}$ At this point in time, OxyContin had become "the most prescribed brand-name narcotic medication for treating moderate-to-severe pain". ${ }^{17}$ By 2003 , the societal implications of OxyContin abuse had become so severe that the US House of Representatives requested the Government Accounting Office (GAO) to investigate and prepare a report on OxyContin abuse and diversion. ${ }^{18}$ While the GAO report did identify aggressive marketing tactics by Purdue Pharma, the report only went so far as to recommend that the FDA ensures "risk management plan guidance encourages pharmaceutical manufacturers that submit new drug applications for these substances to include plans that contain a strategy for monitoring the use of these drugs and identifying potential abuse and diversion problems". ${ }^{17}$

Despite sidestepping direct Congressional action, the marketing tactics used by Purdue Pharma did not escape the attention of the DOJ. On May 10, 2007, Purdue Frederick and Company Inc., an affiliate of Purdue Pharma, pled guilty to felony criminal charges of misbranding OxyContin with intent to defraud or mislead between 1995 and 2001, by claiming that OxyContin was "less addictive and less subject to abuse and diversion than other opioids and less likely to cause tolerance and withdrawal than other pain medications". ${ }^{19}$ The plea agreement imposed $\$ 634.5$ million in penalties, substantially in excess of the statutory maximum of $\$ 5,00,000$ and 5 years of probation for the felony charge. In addition to a $\$ 34.5$ million payment in lieu of imprisonment assessed on three executives pleading guilty to a misdemeanor charge of misbranding, there was an additional $\$ 600$ million to settle a consolidated range of civil actions, with $\$ 130$ million of the settlement going to private civil claims and the remainder to federal and state governments and programs.

The 2007 judicial outcome was not the end of legal troubles for Purdue Pharma, though the type and number of actions has changed considerably. ${ }^{20,21}$ At present, it is difficult to keep track of the number of US lawsuits arising from the prescription opioid epidemic as new actions are being filed almost every day by plaintiffs that include individuals, states, counties, cities, native American tribes, and the federal government. As of March 24, 2018, 450 such suits have been consolidated as an "MDL" by a special panel of authorized federal judges. The cases are to be heard before a single federal judge in the northern district of Ohio (MDL 2804). The MDL is an "unorthodox civil procedure" that is useful for joining cases when class action remedies are not available, as in product liability and health cases where the "individuality of harm" can present problems prosecuting a 
class action..$^{20}$ Defendants include not just Purdue Pharma but an array of manufacturers, distributors, and pharmacy retailers. Included in the causes of action are racketeering, Medicaid fraud, negligence, and unjust enrichment.

The initial promotion and marketing of OxyContin by Purdue Pharma has correctly been described as a "commercial triumph" and a "public health tragedy". ${ }^{9}$ While the extent of legal liability for Purdue Pharma and other firms arising from marketing and distribution of OxyContin and other prescription opioids is still to be determined, the relationship between legal liability and profitability begs an important question regarding the ethics of economic medicalization: is "ethical-is-legal" the appropriate ethical standard to apply to shareholder wealth maximization? As the impressive amount of wealth accumulated by the owners of privately held Purdue Pharma since the introduction of OxyContin illustrates - Forbes estimates the Sackler family fortune at $\$ 13$ billion - the prescription opioid epidemic created by the medical profession may represent a compelling instance where economic medicalization generated more than sufficient expected profits to offset potential legal liability. If this is the case, an ethical-is-legal standard is too stringent. If gain in expected profit exceeds potential litigation costs assumed, then pursuing shareholder wealth maximization could permit a firm to engage in activities that could be construed as illegal. As such, the ethical standard for shareholder wealth maximization is confounded not only by the vagaries of share pricing but also by the vagaries of determining legal liability. Further detailed examination of the defenses used against plaintiff accusations is required.

The 2007 misbranding fraud decision against Purdue Pharma was significant as the first major decision against defendants in a range of lawsuits generated during the early stage of the prescription opioid epidemic. Given the substantial position of OxyContin in prescriptions being diverted for substance abuse, Purdue Pharma was a common defendant in cases brought by a range of plaintiffs including state attorney generals, medical insurance providers, and individuals. Until the 2007 decision, a "no-settlement" approach to litigation had been largely successful..$^{20}$ Defense strategies by Purdue Pharma and other defendants can be roughly divided into two types: legal technicality and ethically substantive. Technical strategies seek to undermine the action on jurisdictional grounds. For example, in private actions claiming that Purdue Pharma violated duties required under the CSA, a counterclaim was that enforcement under the CSA could only be pursued by the regulatory agency and not by a private party. Another instance involving Purdue Pharma occurred in the 7-year litigation with the Commonwealth of Kentucky that commenced in 2007 where, among various delaying tactics, Purdue sought a trial venue in Franklin county, not Polk county, a jurisdiction that had been decimated by the opioid epidemic. $^{22}$

Substantive defenses relate both legal and ethical responsibility. Despite similarities to cases brought against tobacco companies and firearm manufacturers, the prescription opioid epidemic is decidedly more ethically complicated. Unlike tobacco and firearms, prescription opioids have a potentially positive medical value. Physicians responsible for approving use have advanced scientific training and an established code of ethics. In conjunction with Schedule II classification and approval for specific use by the FDA, physicians have a sound ethical and legal basis for issuing prescriptions. Like tobacco but unlike firearms, those most harmed are also those consuming the products. However, diversion of prescription opioids is illegal while tobacco consumption and, with proper licensing, firearm possession are both legal. The illegal action of those being most harmed by prescription opioid diversion is a key component of defense strategies for all types of defendants. "Intervening conduct" of prescribing physicians and patients breaks the legal link between manufacturers and distributors of prescription opioids and the harm caused by the product. ${ }^{20}$ The "ethical-is-legal" implication for manufacturers and distributors is that the opioid epidemic is a consequence of physicians, for some reason, overprescribing combined with substance abusers and addicts illegally diverting and consuming prescription opioids.

For legal purposes, the defense of "intervening conduct" is more complicated for physicians and, in some instances, for pharmacists. Most cases against physicians and pharmacists involve malpractice (professional negligence), though there are instances of criminal prosecutions. In the broader context of the prescription opioid epidemic, malpractice cases pose various problems. It is not enough to demonstrate that physician error in opioid prescribing led to an overdose or that a pharmacist failed to determine that some prescription was being filled by a substance abuser. The negligence must be sufficiently below the professionally required "standard of care," and there must be identifiable harm from the negligence. The standard of care for using opioids in pain management is not clear-cut, and, if the prescription opioids are diverted, then the harm was not suffered by the patient allowing the defense of "intervening conduct". More importantly, malpractice cases involving individual physicians are often associated with overdoses from using methadone in pain management, ${ }^{23}$ not the types of diverted and illegal opioids 
driving the epidemic of overdose deaths. In addition, litigation involving individual physicians cannot possibly address the scope of the prescription opioid epidemic.

An important subtext in the opioid epidemic is the positive social perception of the ethical physician associated with the medicalization process where cultural values regarding violent behavior, end-of-life decisions, substance abuse, capital punishment, childbirth, and the like are being gradually supplanted by perspectives of the medical professional. ${ }^{24-26}$ A fundamental ethical requirement for physicians is "do no harm". However, this dictum applies only to the patient, not to those involved in illegal consumption of diverted prescriptions. Short of overt criminal activity associated with "pill mills" and rogue pharmacies that fill prescriptions with no legitimate medical purpose, malpractice is difficult to assert when the possibility of patient error in taking opioids is compounded by the difficulty of balancing the risks of overand underprescribing. Against this backdrop, there has been concerted effort by the regulators and medical associations to strengthen and clarify the medical basis for using opioids in chronic noncancer pain management. ${ }^{27-30}$ This effort has succeeded in shifting the epidemic vortex from prescription opioids toward illegal opioids that are increasingly contaminated with fentanyl and related opiate derivatives.

\section{Regulation and the opioid abuse epidemic}

A central defense used by manufacturers, distributors, and physicians against various plaintiff actions is that the specific prescription opioid involved has been approved by the FDA, the sole federal authority responsible for assuring drug safety, efficacy, and security. Yet, the November 2017 "Report" by the President's Commission on Combating Drug Addiction and the Opioid Crisis, chaired by Governor Chris Christie, concluded that "The FDA provided inadequate regulatory oversight. Even when overdose deaths mounted ... the FDA accepted claims that newly formulated opioids were not addictive, did not impose clinical trials of sufficient duration to detect addiction, or rigorous post-approval surveillance of adverse events, such as addiction". ${ }^{4}$ The relationship of this serious indictment of FDA performance to the broader opioid crisis is also identified: "The FDA also failed to assess the risks associated with deliberate diversion and misuse of opioids, risks that conceivably outweighed the intended benefits for patients if used as directed." It was not until March 2016, well after tragic consequences of the opioid crisis were apparent, that the FDA "requested from the National Academies of Sciences, Engineering, and Medicine ... a summary of the current status of science regarding prescription opioid abuse and misuse, and the role of opioids in pain management."4

Failure of the FDA to provide adequate regulatory oversight became a moot point once the epidemic of opioid abuse reached frightening and tragic proportions. Attention pivots to policies aimed at alleviating the epidemic. An overview of policy recommendations and evolution of federal policies is provided by comparing two Presidential reports, the 2017 "Report" and a 2011 report prepared by the Obama White House. ${ }^{4,31}$ Both reports have the same general recommendations: "action in four major areas to reduce prescription drug abuse: education, monitoring, proper disposal, and enforcement" (2011); and, "this crisis can be fought with effective medical education, voluntary or involuntary changes in prescribing practices, and a strong regulatory and enforcement environment" (2017). The 2011 report, "Epidemic: Responding to America's Prescription Drug Abuse Crisis", is a brief of 10 pages, with various naïve interpretations of factors driving prescription drug abuse. Reflecting the dramatic evolution of the opioid epidemic since 2011, the 2017 report is 138 pages with a detailed discussion of 56 recommendations in four areas: Federal Funding and Programs; Opioid Addiction Prevention; Opioid Addiction Treatment, Overdose Reversal, and Recovery; and Research and Development.

Emphasis in the 2017 "Report" on Prescription Drug Monitoring Program data, "public health and public safety indicators", and studies to define "specific problems of opioid overuse ... in terms of clinical conditions, provider types, patient characteristics, and practice settings" reflects shortcomings posed by medicalization of the opioid epidemic. Capturing core themes of the "war on drugs", the death toll of substance abuse not within the grasp of the medical profession is, inferentially, a matter for the criminal justice system. $^{32,33}$ Regulatory and legislative schemes and most publications in medical journals intended to address the epidemic of opioid abuse and overdose focus on prescriptions. "Medication-assisted treatment" solutions address those that are accessing the medical system, preferably with private insurance. Connections between introduction of the Affordable Care Act (ACA; 2010) and subsequent evolution of the opioid epidemic focuses on implications of repeal for access to treatment. Parity provided by the ACA is critical "to ensure access to adequate treatment without unfair outof-pocket costs and limits on the frequency and duration of services". ${ }^{34}$ The possibility that parity provided by the ACA contributed to the epidemic by providing enhanced access to opioids to populations prone to prescription diversion is not considered. 
Medicalization implies a perspective on solving the opioid overdose epidemic that maintains the following: "in the history of medicine, science is one of the strongest allies in resolving public health crises. Ending the opioid epidemic will not be any different ... intensified and better-coordinated research is needed to accelerate the development of medications and technologies to prevent and treat these disorders". ${ }^{35}$ The "medical science will save us" ethos is subject to the same criticisms being advanced when the social implications of medicalization were first identified in the late 1950s by Barbara Wootton et al: "It is always easier to build a clinic than to tear down a slum". ${ }^{36}$ Despite claims of "poor-quality evidence", there is significant accumulation of evidence indicating US policies to address the drug overdose epidemic are "ineffective". ${ }^{37}$ One disturbing piece of evidence is that the epidemic of opioid overdose deaths has primarily impacted non-Hispanic whites (see Figures 1 and 4), with a ratio of approximately twice the number of male to female deaths. The surge in nonprescription opioid deaths conflates the prescription opioid epidemic with the "war on drugs" that has been largely targeted at "the poor and people of color who are financially or socially unable to remove themselves from environments that are labeled "drug areas". ${ }^{33}$

The "ineffectiveness" of US policies to deal with the tragic epidemic of drug overdoses and deaths originates in deep-seeded ideological biases and social bigotry that prevent adequate recognition of epidemic fundamentals required to accurately formulate effective policies. Unlike the 2011 report that naively identifies "well-meaning parents [that] do not understand the risks associated with giving prescribed medication to a teenager or another family member for whom the medication was not prescribed" and "leave unused prescription drugs in open medicine cabinets", the 2017 report makes progress in identifying the characteristics of those filling the morgues and presenting as overdoses at emergency departments. Evidence from the SAMHSA 2016 National Survey on Drug Use and Health (NSDUH) detailed in the report has, seemingly, been selectively interpreted in formulating policy. For example, of the staggering 91.8 million reporting use of prescription opioids at some point during 2016, only 11.5 million report varying types of misuse at some point during the year, for example, taking more than the prescribed dosage, with 3.5 million reporting current misuse, leaving 1.6 million classified as having an opioid use disorder (OUD). Policy imposing stringent use guidelines aimed at restricting availability of prescription opioids to curtail diversion imposes considerable hardship on a significant fraction of the 80 million not reporting misuse and benefiting from long-term pain management benefits of opioids, ${ }^{38}$ and encourages the 1.6 million with OUD to seek fentanyl-contaminated supply in the black market with tragic consequences.

Evidence on characteristics of those at risk of prescription opioid overdose and death has been accumulating since abuse of OxyContin and related opioids was recognized as a serious public health problem. By 2010, a variety of detailed

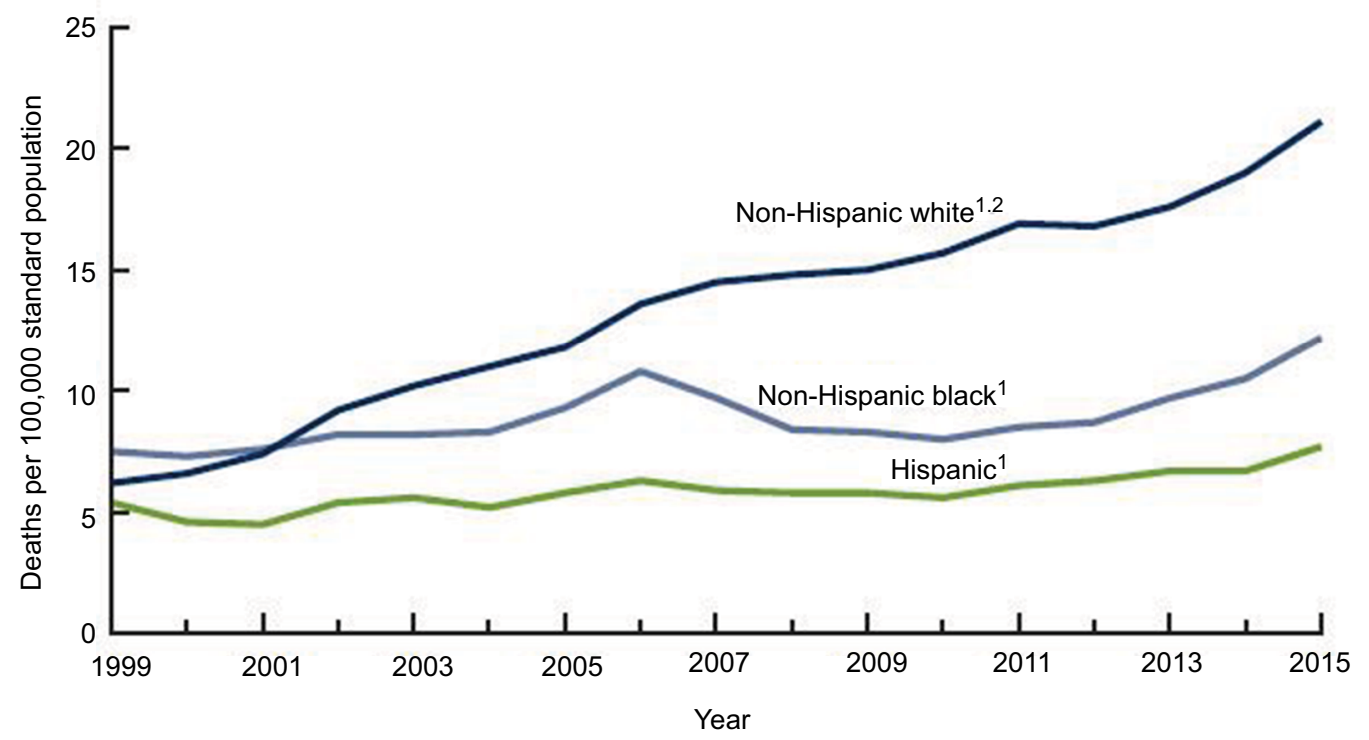

Figure 4 Age-adjusted drug overdose death rates by race and ethnicity: United States, 1999-2015.

Notes: 'Significant increasing trend, $P<0.005$. ${ }^{2}$ Rate for non-Hispanic white persons was significantly higher than for Non-Hispanic black and Hispanic, $P<0.00 \mathrm{I}$. Deaths are classified using the International Classification of Diseases, Tenth Revision. Drug overdose deaths are identified using underlying cause-of-death codes X40-X44, X60-X64, $\mathrm{X} 85$, and Y I0-YI4. Death for Hispanic persons may be underreported by about 5\%. Hedegaard H, Warner M, Miniño AM. Drug overdose deaths in the United States, 1999-2016. NCHS Data Brief, no 294. Hyattsville, MD: National Center for Health Statistics. 2017.58 
academic studies emerged about geographical and demographic distribution of users, ${ }^{2,39}$ patterns of diversion and abuse in high-use areas, for example, rural Appalachia; ${ }^{40,41}$ and, characteristics of abusers. ${ }^{42-44}$ This evidence can be combined with data from the 2016 NSDUH and studies on heroin use, ${ }^{45,46}$ emergency department overdose experience; ${ }^{47}$ relationship between OUD and the homeless; ${ }^{48,49}$ characteristics of methadone overdoses; ${ }^{23,50}$ and, the extent of fentanyl and counterfeit drugs. ${ }^{51-53}$ The picture that emerges from the available data is a complex of subpopulations that are difficult to capture with national programs aimed at "effective medical education, voluntary or involuntary changes in prescribing practices, and a strong regulatory and enforcement environment". Such programs will almost certainly be successful for some subpopulations but potentially counterproductive for others.

Consider evidence from West Virginia Health Statistics Center for a state that, together with Kentucky, contains 15 counties, predominately rural, reporting the nationally highest mortality rate from opioid-related overdose deaths in 2015: "most drug overdose deaths involved multiple substances (polypharmacy), each individual death usually involved multiple types of drugs ... in 2015 ... approximately 3.5 drugs were involved in each fatal overdose". ${ }^{54}$ Similar evidence appears in numerous studies of OxyContin abuse where "the majority of OxyContin users ... were already involved in the use of drugs and used OxyContin to get high and in ways to maximize its psychogenic effects" 43 and "the people who enter treatment programs for OxyContin abuse/dependence are not naive individuals with accidental addiction ... The individuals ... are, for the most part, individuals with extensive drug use and involvement in the criminal justice system". ${ }^{42}$ The NSDUH reports misuse and use disorders of prescription opioids were most common in adults who were uninsured, unemployed, and with low income and behavioral health problems. Those with substance abuse history are at greatest risk of opioid overdose death.

\section{Conclusion}

Solutions to the public health tragedy of prescription opioid abuse and diversion are elusive. The epidemic of substance abuse overdose deaths has societal roots, grounded in poverty, social inequality, and marginalization of affected populations. Against this backdrop, economic medicalization by medical corporations seeking to profit from dramatically increasing the supply of prescription opioids has resulted in the opioid abuse epidemic spilling over into populations not typically impacted by the tragic consequences of addiction and overdose deaths. This has exposed the sharp ethical differences between the medical ethics of physicians responsible for prescriptions and the ethics of medical corporations pursuing shareholder wealth maximization seeking to profit from producing and distributing the opioids. The avalanche of civil and criminal legal actions resulting from the epidemic demonstrates that litigation is too blunt a tool to offset the potential gains of economic medicalization. The upshot is that even if various members of the medical industry act "ethically", it is still possible for there to be an epidemic of prescription opioid abuse.

An important facet of the prescription opioid abuse epidemic is failure by the FDA to provide adequate regulatory oversight. This failure raises legitimate questions about the ability of government to design policies for alleviating the epidemic. Proposed policies emphasize medical education, changes in prescribing practices, and "a strong regulatory and enforcement environment". This approach begs the following question: how will policies aimed at restricting the supply of prescription opioids solve the social problems that lead to addiction and overdose deaths? The ethos of public health policy surrounding prescription opioid abuse is based on a utopian vision of a world without substance abuse and addiction. The road to achieving this vision depends on tight restriction of illegal drugs and prevention of the diversion of legally prescribed opioids. The addict is at fault for not seeking medical treatment. The doctor shoppers and clinics that "overprescribe" for profit are at fault by making supplies available for nonmedical use. Recent reduction in the prescription opioid supply has resulted in substance abusers transitioning to illegal alternatives - heroin, cocaine, benzodiazepines, and methamphetamine - often contaminated by fentanyl with a resulting tragic increase in overdose deaths.

Historically, connecting public health policy with the "war on drugs" has resulted in overflowing prisons and increasing marginalization of addicted populations. Resistance to such consequences has given impetus to "harm reduction" strategies including overdose prevention and supervised injection sites; ${ }^{55}$ increased availability of and training for naloxone (Narcan); "Good Samaritan" laws exempting from prosecution those assisting with overdose victims; and nocost illicit drug testing facilities. Resistance to such policies typically stresses the encouragement of drug abuse and the threat to communities from clients accessing supervised injection site locations. However, despite some substantive gains and claims of success, ${ }^{56}$ the only location in North America that has implemented each of these strategies is still plagued by drug overdose deaths -37 per $1,00,000$ in 
the Vancouver Coastal Health region in 2017. Despite having no drug overdose deaths at the supervised injection site and hundreds of naloxone recoveries, approximately $60 \%$ of 2016 deaths involved fentanyl with about $80 \%$ of illicit drugs tested reporting fentanyl contamination. Undermining the naloxone efforts, in 17 out of 20 overdose deaths, 911 was not called. ${ }^{57}$

\section{Acknowledgments}

Geoffrey Poitras is a Professor of Finance in the Faculty of Business Administration at Simon Fraser University. The author gratefully acknowledges helpful discussions with Lindsay Meredith. Partial support for this research was provided by the Social Sciences and Humanities Research Council of Canada.

\section{Disclosure}

The author reports no conflicts of interest in this work.

\section{References}

1. Rivat $\mathrm{C}$, Ballantyne J. The dark side of opioids in pain management: basic science explains clinical observation. Pain Rep. 2016;1(2):e570.

2. Poitras G. OxyContin, prescription opioid abuse and economic medicalization. Medicoleg Bioeth. 2012;2:31-43.

3. Rudd RA, Aleshire N, Zibbell JE, Gladden RM. Increases in drug and opioid overdose deaths - United States, 2000-2014. MMWR Morb Mortal Wkly Rep. 2016;64(50-51):1378-1382.

4. Report of the President's Commission on Combating Drug Addiction and the Opioid Crisis. Available from: https://www.whitehouse.gov/ sites/whitehouse.gov/files/images/Final_Report_Draft_11-1-2017.pdf. Accessed November 1, 2017.

5. Cohen MJ, Jangro WC. A clinical ethics approach to opioid treatment of chronic noncancer pain. AMA J Ethics. 2015;17(6):521-529.

6. Novy DM, Ritter LM, Mcneill J. A primer of ethical issues involving opioid therapy for chronic nonmalignant pain in a multidisciplinary setting. Pain Med. 2009;10(2):356-363.

7. Poitras G, Meredith L. Ethical transparency and economic medicalization. J Business Ethics. 2009;86(3):313-325.

8. Borchers AT, Hagie F, Keen CL, Gershwin ME. The history and contemporary challenges of the US Food and Drug Administration. Clin Ther. 2007;29(1):1-16.

9. van Zee A. The promotion and marketing of oxycontin: commercial triumph, public health tragedy. Am J Public Health. 2009;99(2):221-227.

10. Hedegaard H, Warner M, Miniño AM. Drug overdose deaths in the United States, 1999-2016. NCHS Data Brief, no. 294. Hyattsville, MD: National Center for Health Statistics. 2017.

11. Centers for Disease Control (CDC). Vital signs: changes in opioid prescribing in the United States, 2006-2015. MMWR Morb Mortal Wkly Rep. 2016;66:697-704.

12. Centers for Disease Control and Prevention (CDC). CDC grand rounds: prescription drug overdoses - a U.S. epidemic. MMWR Morb Mortal Wkly Rep. 2012;61(1):10-13.

13. Humphreys K. Avoiding globalisation of the prescription opioid epidemic. Lancet. 2017;390(10093):437-439.

14. Los Angeles Times [webpage on the Internet]. OxyContin goes global - "We're only just getting started" [updated December 18, 2016]. Available from http://www.latimes.com/projects/la-me-oxycontin-part3/. Accessed September 3, 2018.

15. Humphreys K, Caulkins J, Felbab-Brown V. Opioids of the masses: stopping an American epidemic from going global. Foreign Affairs. 2018;97(3):118-129.
16. Häuser W, Schug S, Furlan AD. The opioid epidemic and national guidelines for opioid therapy for chronic noncancer pain: a perspective from different continents. Pain Rep. 2017;2(3):e599:1-11.

17. Government Accounting Office. OxyContin abuse and diversion and efforts to address the problem: highlights of a government report. J Pain Palliat Care Pharmacother. 2004;18(3):109-113.

18. GAO. OxyContin Abuse and Diversion and Efforts to Address the Problem. Washington, DC: GAO-04-110; 2003.

19. United States of America vs. The Purdue Fredrick Company Inc. et al (WD Va., May 10, 2007, Case 1:07CR00029): 2.

20. Gluck AR, Hall A, Curfman G. Civil litigation and the opioid epidemic: the role of courts in a national health crisis. SSRN Electron J. 2018:1-30.

21. Haffajee RL, Mello MM. Drug companies' liability for the opioid epidemic. N Engl J Med. 2017;377(24):2301-2305.

22. Commonwealth of Kentucky et al v. Purdue Pharma, L.P. et al (ED Kentucky, June 5, 2015, Case No. 7:07-cv-00222).

23. Rich BA, Webster LR. A review of forensic implications of opioid prescribing with examples from malpractice cases involving opioidrelated overdose. Pain Med. 2011;12(Suppl 2):S59-S65.

24. Smith DE. Medicalizing the opioid epidemic in the U.S. in the era of health care reform. J Psychoactive Drugs. 2017;49(2):95-101.

25. Nye RA. The evolution of the concept of medicalization in the late twentieth century. J Hist Behav Sci. 2003;39(2):115-129.

26. Conrad P. The Medicalization of Society. Baltimore, MD: Johns Hopkins Press; 2007.

27. Centers for Disease Control (CDC). CDC guideline for prescribing opioids for chronic pain - United States, 2016. MMWR Morb Mortal Wkly Rep. 2016;65:1-49.

28. Food and Drug Administration (FDA). FDA opioids action plan. Available from: https://www.fda.gov/drugs/drugsafety/informationbydrugclass/ucm484714.htm. Accessed July 11, 2017.

29. Chou R, Fanciullo GJ, Fine PG, et al. Clinical guidelines for the use of chronic opioid therapy in chronic noncancer pain. $J$ Pain. 2009;10(2):113-130.

30. Qaseem A, Wilt TJ, McLean RM, Forciea MA. Clinical Guidelines Committee of the American College of Physicians. Noninvasive treatments for acute, subacute, and chronic low back pain: a clinical practice guideline from the American College of Physicians. Ann Intern Med. 2017;166(7):514-530.

31. House W. Epidemic: Responding to America's Prescription Drug Abuse Crisis, Washington, DC; 2011. Available from: https://obamawhitehouse.archives.gov/sites/default/files/ondcp/policy-and-research/ rx_abuse_plan.pdf. Accessed March 31, 2018.

32. Netherland J, Hansen HB. The war on drugs that wasn't: wasted whiteness, "Dirty Doctors," and race in media coverage of prescription opioid misuse. Cult Med Psychiatry. 2016;40(4):664-686.

33. Moore LD, Elkavich A. Who's using and who's doing time: incarceration, the war on drugs, and public health. Am J Public Health. 2008;98(5):782-786.

34. Friedmann PD, Andrews CM, Humphreys K. How ACA repeal would worsen the opioid epidemic. $N$ Engl J Med. 2017;376(10):e16.

35. Volkow ND, Collins FS. The role of science in addressing the opioid crisis. N Engl J Med. 2017;377(4):391-394.

36. Wootton B. Social Science and Social Pathology. Seal VG, Chambers R, editors. New York: Macmillan; 1959:206.

37. Weeks WB, Goertz CM. Ineffective policies to address the opioid epidemic. JAMA Psychiatry. 2017;74(9):974.

38. Glod SA. The other victims of the opioid epidemic. $N$ Engl J Med. 2017;376(22):2101-2102.

39. Warner M, Chen L, Makuc D, Anderson R, Miniño A. Drug poisoning deaths in the United States, 1980-2008. NCHS Data Brief. 2011;81:1-8.

40. Jonas AB, Young AM, Oser CB, Leukefeld CG, Havens JR. OxyContin ${ }^{\circledR}$ as currency: OxyContin ${ }^{\circledR}$ use and increased social capital among rural Appalachian drug users. Soc Sci Med. 2012;74(10):1602-1609.

41. Jones JD, Vosburg SK, Manubay JM, Comer SD. Oxycodone abuse in New York City: characteristics of intravenous and intranasal users. $\mathrm{Am}$ JAddict. 2011;20(3):190-195. 
42. Carise D, Dugosh KL, Mclellan AT, Camilleri A, Woody GE, Lynch KG. Prescription OxyContin abuse among patients entering addiction treatment. Am J Psychiatry. 2007;164(11):1750-1756.

43. Levy MS. An exploratory study of OxyContin use among individuals with substance use disorders. J Psychoactive Drugs. 2007;39(3):271-276.

44. Sees KL, di Marino ME, Ruediger NK, Sweeney CT, Shiffman S. Nonmedical use of OxyContin tablets in the United States. J Pain Palliat Care Pharmacother. 2005;19(2):13-23.

45. Cicero TJ, Ellis MS, Surratt HL, Kurtz SP. The changing face of heroin use in the United States: a retrospective analysis of the past 50 years. JAMA Psychiatry. 2014;71(7):821-826.

46. Compton WM, Jones CM, Baldwin GT. Relationship between nonmedical prescription-opioid use and heroin use. N Engl J Med Overseas Ed. 2016;374(2):154-163.

47. Yokell MA, Delgado MK, Zaller ND, Wang NE, Mcgowan SK, Green TC. Presentation of prescription and nonprescription opioid overdoses to US emergency departments. JAMA Intern Med. 2014;174(12): 2034-2037.

48. Riley ED, Cohen J, Shumway M. Overdose fatality and surveillance as a method for understanding mortality trends in homeless populations. JAMA Intern Med. 2013;173(13):1264-1265.

49. Ries R, Krupski A, West II, et al. Correlates of opioid use in adults with self-reported drug use recruited from public safety-net primary care clinics. J Addict Med. 2015;9(5):1-26.

50. Centers for Disease Control and Prevention (CDC). Overdose deaths involving prescription opioids among Medicaid enrollees - Washington, 2004-2007. MMWR Morb Mortal Wkly Rep. 2009;58(42): 1171-1175.
51. Green TC, Gilbert M. Counterfeit medications and fentanyl. JAMA Intern Med. 2016;176(10):1555-1557.

52. Cicero TJ, Ellis MS, Kasper ZA. Increases in self-reported fentanyl use among a population entering drug treatment: the need for systematic surveillance of illicitly manufactured opioids. Drug Alcohol Depend. 2017;177:101-103.

53. O’Donnell JK, Halpin J, Mattson CL, Goldberger BA, Gladden RM. Deaths involving fentanyl, fentanyl analogs, and U-47700 - 10 States, July-December 2016. MMWR Morb Mortal Wkly Rep. 2017;66(43): 1197-1202.

54. West Virginia Department of Health and Human Resources. West Virginia Drug Overdose Deaths, Historical Overview 2001-2015; 2017:4

55. Wakeman SE. Another senseless death - the case for supervised injection facilities. N Engl J Med. 2017;376(11):1011-1013.

56. Wood E. Strategies for reducing opioid-overdose deaths - lessons from Canada. N Engl J Med. 2018;378(17):1565-1567.

57. BC Centre for Disease Control. The opioid overdose emergency; 2017. Available from: http://www.bccdc.ca/resource-gallery/Documents/ opioid od emergency bw 20170606 - BW.pdf. Accessed March 8, 2018

58. Hedegaard H, Warner M, Miniño AM. Drug overdose deaths in the United States, 1999-2016. NCHS Data Brief, no 294. Hyattsville, MD: National Center for Health Statistics. 2017.
Medicolegal and Bioethics

\section{Publish your work in this journal}

Medicolegal and Bioethics is an international, peer-reviewed, open access journal exploring the application of law to medical and drug research and practice and the related ethical and moral considerations. The journal is characterized by the rapid reporting of reviews, case reports, guidelines and consensus statements, original research

\section{Dovepress}

and surveys. The manuscript management system is completely online and includes a very quick and fair peer-review system. Visit http://www.dovepress.com/testimonials.php to read real quotes from published authors. 